\title{
FRONTERA, HISTORIA Y LITERATURA
}

\author{
A Antonio Alatorre, \\ que supo oír las voces de los escritores \\ jóvenes de los sesenta, y confió en el futuro \\ La música fluye a través de la extensa fila. \\ Es imposible detenerla, cruza la frontera \\ primero que nosotros, su caudal es ingobernable ${ }^{1}$.
}

HACIA UN CONCEPTO DE FRONTERA QUE VINCULE

LA LITERATURA Y LA HISTORIA

Un repaso del discurso crítico, por somero que sea, evidencia la pluralidad de formas en que se utiliza la noción de frontera. $\mathrm{Si}$ bien conceptualmente esto indica cierto grado de dispersión e imprecisión, por lo general se insiste en el uso del vocablo, y se especifican sus diversas modalidades, lo cual indica una aceptación básica de su eficacia. Pienso que esto remite a la concepción de frontera como una perspectiva, un modo particular de "mirar", sin duda propicio para captar aspectos nucleares de nuestro tiempo, nuestras geografías y modos individuales y colectivos de relacionarnos.

Esta perspectiva crítica es decisiva sobre todo para un mundo en tránsito hacia un cambio de paradigma, o simplemente para responder con mayor eficacia a una concepción del devenir histórico-social como proceso que importa captar con toda

1 Luis Humberto Crosthwaite, "Diez minutos de futuro", en Instrucciones para cruzar la frontera. Relatos, Joaquín Mortiz, México, 2002, p. 123. 
la riqueza de sus contradicciones. Los cortes necesarios, para deslindar los objetos parciales de estudio o de observación, si se establecen con esta perspectiva, no entrarán en contradicción con el dinamismo de los procesos. Atento a esta necesidad de encontrar caminos más eficaces para estudiar las manifestaciones culturales y artísticas de nuestro tiempo, Frederic Jameson propuso para lograrlo el estudio de las imágenes, determinantes en la literatura, la pintura, la arquitectura y diría también el teatro y el cine. Después, señala el investigador David Spener², el antropólogo Roger Rouse ofrece ampliar la propuesta de Jameson, e incluir "detalles de la vida cotidiana de la gente" para poder captar la postmodernidad. De hecho la cotidianidad ha sido un componente siempre presente en la literatura, incorporado, desde mucho antes, como noción de análisis. Se entiende sin embargo que el énfasis es propicio a un tiempo histórico que se nos escapa para comprenderlo en su complejidad. Al disminuir la posibilidad de totalización en el conocimiento del suceder histórico social, se recae en la experiencia inmediata como el laboratorio propicio para entendernos. La tendencia se extiende al pasado. El escritor y el estudioso buscan imaginar, re-crear la vida cotidiana y el modo de vivirla los hombres y mujeres de su tiempo, enfoque frecuente hoy en trabajos medievalistas (Le Goff) y de la cultura novohispana en América. La literatura y el discurso crítico se identifican con la vida cotidiana y cómo la viven sus actores medios, y desde ahí proyectan el futuro. No sorprende que en momentos así se vuelva la vista hacia la literatura de la tradición oral y popular, y hacia las tradiciones populares de otras artes como la música y la danza. Esta tendencia va casi siempre de la mano con la perspectiva en frontera desde donde se observa el devenir histórico-social. Cuando se miran con este enfoque los géneros tradicionales, se percibe el movimiento de la pluralidad de formas, sentidos y tradiciones asumidas a lo largo de los años; se explica su devenir entre la tradición y la transformación; entre la tradición y el cambio, y con ello, su particular modo de acercarnos a la historia social y de ubicarnos en ella. Así, por ejemplo, mirar la décima y la glosa en décimas tradicionales con esta perspectiva, confirma que se trata de un género panhispánico, presente en

2 "Narrativas del mal: el coyote mexicano en el drama del cruce fronterizo", en Más allá de la ciudad letrada: crónicas y espacios urbanos, eds. B. Muñoz y S. Spitta, Pittsburgh University Press, Pittsburgh, 2003, pp. 379-409. 
prácticamente todo el continente hispanoamericano y en Brasil, con un origen culto peninsular (Sur de España, Portugal), donde ya el género de la Corte se estaba prosificando, y que en América se vuelve forma tradicional dominante e incluso contestataria vía el pasquín, el pliego de cordel, la hoja suelta, las controversias los certámenes, etc. ¿Cómo una forma culta, compleja en su composición, se transforma en un bien popular que atraviesa todo el continente y al mismo tiempo se particulariza en cada país? ¿Qué había en esta orilla que popularizó este género con sus variantes musicales, rituales, performances, etc.? Investigo a partir de una metodología integral que toma en cuenta la complejidad de estas formas y procesos ${ }^{3}$. Baste decir por ahora que, en tanto forma, la glosa en décimas conjuga la copla y la décima y un sistema de repeticiones que marca el hecho de ser glosada y las relaciones con la música. Otras hibridaciones fronterizas, propias del género: épica y lírica, "culto" y "popular"; oralidad y escritura; canto y poesía; improvisación y memoria; canon y transgresión.

Sin pretender llegar a conclusiones definitivas, me parece importante repensar el concepto de frontera; iniciar deslindes que tomen en cuenta la diversidad y la diferencia o, más bien, la diferencia de nuestro estar en la historia.

En el orden de la geografía y de la cultura es necesario apuntar que las fronteras están cruzadas por tendencias culturales y sociales que "mueven" los límites y transforman las líneas divisorias en espacios que propician el intercambio social, y el hibridismo cultural, lo que Maureen Ahern denomina "fronteras de transformación y continuidad" para referirse al cruce de culturas en la literatura novohispana. A esto se suma la confluencia de las diversas etnias, entre las cuales predominan la

3 Cf. mis artículos: "Oralidad y escritura: las décimas de Colón en México y Puerto Rico”, en Actas XXIX Congreso del Instituto Internacional de Literatura Iberoamericana, Universitat de Barcelona, Barcelona, 1992, pp. 437451; "Tradicionalidad y escritura en las décimas y glosas de México y otros países hispanoamericanos", en VI Encuentro-Festival Iberoamericano de la décima y el verso improvisado, t. 1: Estudios, eds. Maximiano Trapero, Eladio Santana Martel y Carmen Márquez Montes, Universidad de Las Palmas de Gran Canaria, Madrid, 2000, pp. 59-72; "Género en fronteras: la glosa en décimas (La Sierra Gorda y otros pueblos vecinos)", en Actas del XV Congreso de la Asociación Internacional de Hispanistas. "Las dos orillas", t. 1: Literatura tradicional, eds. B. Mariscal y A. González, F.C.E.-Asociación Internacional de Hispanistas-Tecnológico de Monterrey-El Colegio de México, México, 2007, pp. 529-543. 
africana con sus derivados en Europa y América, las indígenas o prehispánicas en "las dos orillas" y la "blanca" o criolla europeizante, cuyo mestizaje, sin embargo, está ya presente desde antes de llegar a las tierras del Nuevo Mundo. El modo de organización se altera y restablece según lo demandan las nuevas circunstancias. El espacio, en niveles mínimos de desarrollo, cambia conforme al alza de los niveles económicos, y puede llegar a transformarse en ciudad, como ocurre con la Frontera Norte en México, como se verá después. Revelar las contradicciones de este espacio "urbano" emergente, muchas veces aparencial, en tanto enmascara la pérdida de referentes o la crisis de identidad colectiva y de los sujetos, que aún no se resuelve, es lo que subyace al concepto de "frontera de cristal" que Carlos Fuentes acuña en su libro La frontera de cristal, una novela en nueve cuentos ${ }^{4}$. El título asume ya la condición de frontera (Frontera del Norte) y el género en frontera que vincula la relación unitaria del libro y la autonomía de los fragmentos, lo cual recuerda la organización de El Llano en llamas, claro antecedente de la estructura básica de composición en Pedro Páramo ${ }^{5}$.

Así como todo proceso de exilio provocado por condiciones externas al sujeto tiene su correlato en el exilio interior, es decir, en la experiencia de exiliado que prevalece al interior del individuo, las fronteras hasta aquí esbozadas constituyen la manifestación de las fronteras exteriores que condicionan la vida social y cultural. Éstas repercuten en diversas manifestaciones internas de los individuos, y generan las fronteras interiores: zonas de asimilación de diversas actitudes, sentimientos, ideas, cosmovisiones, que transforman y condicionan las visiones de mundo y los parámetros cognitivos de los sujetos.

La noción de frontera parecería, pues, desplazarse entre la idea de límite y la de intercambio. En tanto límite, deslinda, acota; en tanto zona de intercambio, entra en diálogo con lo otro. De ahí que las fronteras se establezcan, y se deslinden, para rebasarlas, observación que tiende a ver la frontera más que como un área de enfrentamiento, como una posibilidad de intercambio pluricultural y de hibridismos con los cuales se ensayan alternativas de sobrevivencia y de posibilidades de diá-

4 Aguilar-Altea-Taurus-Alfaguara, México, 1995.

5 Sobre este punto, cf. Y. Jiménez de BÁEz, Juan Rulfo: del páramo a la esperanza. Una lectura crítica de su obra, $2^{\mathrm{a}}$ ed., F.C.E., México, 1994, pp. 129131 (1ª ed., El Colegio de México-F.C.E., 1990). 
logo. La manera como enfrentemos la frontera condiciona en mucho las posibilidades de futuro. El epígrafe de este trabajo muestra cómo una línea fronteriza "organizada" y ordenadora, avalada por leyes migratorias restrictivas, que actúa como filtro de ingreso y regreso, es transgredida por el arte y la creación. La escritura escoge la música para simbolizar esta posibilidad deseada de una frontera abierta al tránsito en libertad (volveré sobre este texto). En el caso de la Frontera Norte de México, por ejemplo, lo que importa destacar después de la Segunda Guerra Mundial, es una concepción incluyente de la frontera como zona de contacto entre grupos plurales (étnicos, culturales, nacionales) y no, como pretendía Turner, una zona de enfrentamiento entre "la civilización y el salvajismo", interpretación análoga a la ya clásica de Sarmiento de "civilización y barbarie" 6 . Y sobre todo, desde el punto de vista de los mexicanos, supone un cambio de mira decisivo, frente al sentido prevaleciente de la frontera como "ruptura", "mutilación territorial", "herida abierta", "fractura", a partir de la pérdida de la mitad del territorio nacional, en $1848^{7}$.

La condición de frontera en diversos tiempos y espacios ha llevado a que se desdibujen sus bordes ¿se expandan?, dando lugar a una amplia gama de mestizajes culturales e hibridismos étnicos y geográficos. En lo individual, ser fronterizo es estar en el límite. A su vez, es encontrar al otro, a los otros, y generar nuevos y plurales modos de relación, sin diluirse en ellos. La frontera implica, pues, ponerse en juego. Es un espacio donde el dialogismo facilita que se muestren mejor las simpatías y diferencias; las contradicciones que ponen muchas veces en crisis la propia identidad e incluso la historia (aspectos que cabe asociar también con la noción de puesta en umbral bajtiniana). Pero, al mismo tiempo, nos revela en profundidad lo que somos

${ }^{6}$ Frederick Jackson Turner, "El significado de la frontera en la historia americana”, Secuencia, 7 (1987), núm. 1, 187-207. Sobre este punto cabe destacar la reinterpretación que hace Jorge Bustamante en "Frontera México-Estados Unidos: reflexiones para un marco teórico”, Estudios sobre las Culturas Contemporáneas (Colima), 4 (1991), núm. 11, 11-35. También, y en tanto se recogen éstos y otros aspectos fundamentales, cf. Miguel Olmos Aguilera (ed.), Alteridad, historia e identidad más allá de la línea, El Colegio de la Frontera Norte-Porrúa, México, 2007.

7 José Manuel Valenzuela Arce, "Centralidad de las fronteras. Procesos socioculturales en la frontera México-EE.UU", en Fronteras de la modernidad en América Latina, eds. H. Herlinghaus y M. Moraña, Instituto Internacional de Literatura Iberoamericana, Pittsburgh, 2003, pp. 159-182. 
(me descubro ante los otros y con los otros), y el aquí y el ahora de nuestra particularidad histórica. Cuando los procesos de transculturación ocurren en zonas donde el contacto intercultural es constante, y se van desdibujando los nexos primarios del origen, emergen los signos de una nueva cultura marcada por la hibridación de sus componentes, tal como sucedió con la cultura chicana del sur de Estados Unidos.

No obstante, este "descubrirme otro, en el otro", puede llevar a distanciamientos retadores que refuercen las fronteras como límites, acorde con la acepción original del concepto como un "situarme frente al otro" . Esto es sobre todo evidente en determinados contextos histórico-políticos relacionados con esferas de poder y sus mecanismos frecuentes de opresión y subordinación. Marcar la frontera tiene entonces el efecto de la denuncia: muestra lo que subyace tras la apariencia de bienestar y equilibrio, lo cual nos obliga a elegir: exige una respuesta. Llevada a un límite extremo, como en los gobiernos totalitarios, la frontera es límite infranqueable. Se opone a la vida y la niega. Sobrepasarla es transgredirla y se aproxima a los límites de la muerte. Para Todorov esto se debe a que la práctica del mal en el siglo xx llegó a límites insospechados de divisiones entre los hombres: "la fragmentación del mundo, la despersonalización de las relaciones humanas"; pero "esa fragmentación interior es el efecto de la especialización creciente que reina en el mundo del trabajo, y de su compartimentación inevitable; la despersonalización proviene de una transferencia del pensamiento instrumental al dominio de las relaciones humanas... La especialización y la eficacia se apodera[n] también de las actividades intersubjetivas" 9 .

En uno y otro de los extremos posibles, hay núcleos de arraigo que subsisten en la hibridación y crean las contradicciones observables a una mirada fina de los componentes. Por ejemplo, los interrogantes claves del ¿quién soy?, ¿de dónde soy?, hechos desde la frontera interior y ante la frontera de la muerte,

8 Varios autores, al hablar de frontera, parten de esta relación en el origen del término, y desde ahí incursionan en el proceso histórico de sus transformaciones. Véase, por ejemplo, Nicole Guilleux, "Pour une définition de la frontière, entre lexique et droit," en A propos de frontière. Variations socio-critiques sur les notions de limite et de passage, ed. B. Fouques, L.E.I.A-Université de Caen-Peter Lang, Bern, 2003, pp. 1-3.

9 Tzvetan Todorov, Frente al límite, trad. F. Álvarez, Siglo XXI Editores, México, 1993, pp. 305-306 (1 $1^{\text {a }}$ ed. en fr., Du Seuil, 1991). 
revelan que "el verdadero regreso" del migrante mexicano, como bien lo consignan en su sensible ensayo-testimonio, Raúl Dorantes y Febronio Zatarain, es al morir. Enterrar en sagrado deviene enterrar en la Tierra del origen, su pueblo ${ }^{10}$. Es lo que muestra también la literatura fronteriza. En el relato de Antonio Parra, "La piedra y el río", que precede su libro Tierra de nadie ${ }^{11}$, el personaje principal es Dolores, la esposa que no emigra y vive ante el río límite de la frontera, en espera del regreso. Con el transcurrir de los años, la espera y la frontera se identifican en ella ("madrecita" de los migrantes; peregrina; mujer-río, leyenda: Frontera). A diferencia de las mujeres y los viejos de "Luvina", el cuento de Juan Rulfo, quienes inmersos en la pobreza del cerro no emigran para no dejar a sus muertos, Dolores emigra, de su pueblo de origen, a su peña frente al Río Bravo, y lleva con ella a sus muertos, los cuales entierra "sin cruz, sin lápida" (véase primer epígrafe), con un gesto que funde su Tierra de origen con la nueva tierra fronteriza. Y ella queda ahí, hasta morir en las aguas del río: "Cargó con los huesos de los difuntos desde el otro Laredo y los enterró por el recodo, sin cruz, sin lápida. Desde entonces se quedó a vivir cerca de los muertos y cerca del Bravo" (p. 15).

Considero que el discurso literario reproduce en mucho estos rasgos que he trazado respecto a la noción de frontera. La literatura crea sus mundos de ficción. Todos ellos, aún los que parecen más alejados de los contextos sociohistóricos y culturales, guardan con éstos una relación "indirecta", en tanto se desvían de la norma discursiva de otros textos (históricos, sociológicos, científicos) tradicionalmente asociados a objetivos que implican necesariamente la relación con la historia social y la cultura. Sin embargo, si descodificamos adecuadamente los textos literarios, en su particular tratamiento del lenguaje, percibiremos que el contacto con la historia se especifica precisamente allí donde los demás discursos, por lo general, marcan sus límites. La literatura muestra las relaciones de los hombres y de las mujeres y su repercusión en la subjetividad de su mundo afectivo. Situada desde los márgenes, o desde la cotidianidad, puede incluso mostrar los mecanismos del contexto

10 Raúl Dorantes y Febronio Zatarain, ... Y nos vinimos de mojados. Cultura mexicana en Chicago, pról. de Carlos Monsiváis, Universidad Autónoma de la Ciudad de México, México, 2007, pp. 47-49.

11 Era, México, 1999, pp. 13-26. Históricamente se denominó “Tierra de nadie" al territorio mostrenco de la frontera. 
social y de las instituciones de poder, por los efectos en la vida de los hombres y mujeres de diversas épocas y espacios. Escribir desde los márgenes implica entonces no hacerlo desde las tendencias dominantes, sino más bien desde los espacios que suponen actitudes críticas que contrapuntean el canon y el poder. Equivale a mirar en frontera el contexto y los textos, de tal manera que se observen las contradicciones y se muestren los procesos con la riqueza de su dinamismo. Estas relaciones manifestadas o connotadas en el texto literario varían de acuerdo con la intención que opera en todos los estratos textuales.

Concebir así el texto literario aproxima, como nunca antes tal vez en la historia de la crítica, el discurso literario y el histórico, por lo menos en una de sus modalidades más actuales. En el campo de la Historia en México cabe destacar la aparición de Pueblo en vilo. Microhistoria de San José de Gracia de Luis González ${ }^{12}$, libro que se funda en el análisis de este pueblo de la región michoacana a partir del cual se crea el puente con la macrohistoria nacional, y textos como los de la historiadora Pilar Gonzalbo ${ }^{13}$ que se asientan en la vida cotidiana y en los intersticios de los documentos en tanto estos revelan el "dolorido sentir" colectivo que al mismo tiempo permite caracterizar una época, un sector, así como hace muchos años José Gaos se preocupó quizás más por el estudio de las mentalidades, por la vida en el transcurso de un día o por la Antropología filosófica que encontraba sus bases en textos poéticos que analizaba en clases, con sus alumnos, en la década de los años cincuenta del siglo xx. Pero es Michel De Certeau quien da carácter teórico a esta concepción de la historia y la generaliza, a partir del presente y de una reubicación de la disciplina de cara al desarrollo de las ciencias actuales ${ }^{14}$. Reconocimiento análogo a la calidad

12 El Colegio de México, México, 1968. La aparición del libro en 1968 fue sintomática de los estudios regionales contextualizados en un ámbito de proyecciones nacionales e internacionales, propio de la sociedad cambiante de los años sesenta, en México y otros países.

${ }^{13}$ La vida cotidiana, como noción de análisis, en México recorre prácticamente toda la obra de Pilar Gonzalbo. Baste remitir a un reciente libro suyo, síntesis individual y colectiva de los diversos aspectos de esa noción, explícitos o implícitos en la trayectoria de su obra como historiadora: PILAR Gonzalbo Aizpuru, Introducción a la historia de la vida cotidiana, El Colegio de México, México, 2006.

${ }^{14}$ La escritura de la historia, trad. J. López Moctezuma, Universidad Iberoamericana, México, 1993. 
discursiva de la historiografía que ya ha sido aquilatada desde hace muchos años.

Al perder su "función totalizadora" la historia ya no pretende "sustituir a la filosofía" en el oficio de indicar el sentido de las cosas. Reivindica para sí, como la literatura (Althusser), una función crítica, en su caso, de "los modelos sociológicos, económicos, psicológicos o culturales". Se regresa al detalle de los hechos, para captar no una "realidad", sino el detalle que marca una excepción: la diferencia. Sin pretender la conciliación de la información que le ofrecen los diversos "sistemas de interpretación", busca más bien "las manifestaciones complejas de las diferencias". Si el hecho histórico es ahora la diferencia, se trata de un concepto que parte de una relación, es decir, se trata también de una mirada en frontera. El historiador deviene un tejedor del conocimiento fragmentado. Combina y marca "los cruzamientos, las condiciones de posibilidad y los límites de validez". Ejerce con cada una de las disciplinas del conocimiento "una función crítica necesaria", y tenderá a articular los límites diferenciales ("ausencias significativas y jerarquizables") porque provienen de resultados científicos actuales.

Hasta aquí lo que, por ahora, me interesa destacar de De Certeau $^{15}$ para aproximarnos a la cercanía demostrable que tienen hoy la función y el oficio del historiador y del crítico literario. También para marcar la diferencia, pues si bien la óptica y la base que conforma los objetos de análisis tienden a analogarse, el texto literario se concretiza mediante un trabajo sobre el lenguaje que busca ejercer la función poética en términos de un principio de economía y síntesis que tensa la función metafórica y expresiva del lenguaje, mientras la escritura del historiador buscará sistematizar y explicar; llenar los vacíos de la investigación, mediante la interpretación que se arriesga para escribir con la certeza de quien tiene claro su objetivo. Si el escritor se asienta en la sugerencia, en la connotación, y expresa incluso lo inefable, no pretende en primera instancia mostrar su escritura como acabada en el orden del sentido. Cabría decir que está más próximo a la vivencia y que su lenguaje alcanza por la vía metafórica y otras estrategias poéticas su objetivo. En cambio la escritura de la historia pondrá límites más definidos y se suele basar fundamentalmente en un orden cronológico

${ }^{15}$ El pasaje parafraseado corresponde a la sección "El trabajo sobre el límite” del libro antes citado de De Gerteau, pp. 93-97. 
que revela el proceso libre de las rupturas que provocaría la presencia en primer plano de la subjetividad ${ }^{16}$.

Sin duda, nuestra realidad hispanoamericana es paradigmática, casi por definición de su historia, para ser mirada desde esta perspectiva en frontera. Por un lado nos interrelacionan una lengua y una historia cultural que interactúan con otras lenguas y culturas dentro de cada uno de nuestros países, lo cual permite hablar de panhispanismo o hispanismo, término este último de uso más frecuente en el ámbito estadounidense. O comparte esta designación con la de Latinoamérica, con lo cual abrimos el margen a la cultura de origen lusitano (Portugal) en la otra orilla y Brasil en ésta. Interrelación que prevalecía en la Península desde mucho antes de la llegada de los españoles a América, lo cual explica el tronco común en tantas manifestaciones de nuestras culturas. Pero la tendencia transgeográfica y transcultural, subraya al mismo tiempo la necesidad de un deslinde que muestre la diferencia, la particularidad de cada entidad. Para hablar de zonas lingüísticas o culturales es imprescindible marcar las particularidades que reconocemos diseminadas conforme a los diversos procesos. Lo mismo para reconocer las transgresiones, la creatividad generadora de alternativas...: la diferencia.

En la conformación de la literatura y la cultura latinoamericanas está siempre presente esta tensión entre las particularidades nacionales y regionales y las tendencias que permiten pensarnos, analizarnos y asumirnos como un cuerpo plural que se deslinda, a su vez, de otros, o se relaciona, a su vez, con otros.

El adjetivo "hispano" se ha teñido en la Frontera Norte y en todo espacio del territorio norteamericano donde se congregan y viven grupos de procedencia latinoamericana que son, por lo general, migrantes. Para el filósofo Enrique Dussel $^{17}$ es imprescindible reconocer que el hispano se ubica "entre... muchos mundos que van constituyendo, en el border

16 Cuando De Certeau (ibid., pp. 98-103) comenta esta ambigüedad del discurso histórico al iniciarse el acto de escribir, frente a la ruptura del canon en el proceso de investigación, parece sugerir implícitamente que habrá que hacer ajustes entre la institución de la disciplina que impone esa forma de escritura y lo que implica el cambio hacia una apertura mayor con conciencia de los límites cognoscitivos, en la preparación y la búsqueda anterior.

17 Enrique Dussel A., “'Ser hispano': un mundo en el border de muchos mundos”, en Fronteras de la modernidad en América Latina, p. 231. 
intercultural, una identidad histórica, no sustancialista ni esencialista, sino dialécticamente creadora de sus propios componentes en el proceso mismo de la historia en continua integración de nuevos desafíos". A su vez, debe basarse en una autoafirmación digna y positiva de su propio valer, máxime cuando en la "sociedad hegemónica" norteamericana ocupan el último lugar. Es pues, una cultura de los márgenes, cuando históricamente es el primer heredero de una rica cultura milenaria prehispánica y de una cultura española a su vez heredera de fenicios, romanos y de una España de la Armada Invencible que antecede, por un siglo, a Inglaterra y a Holanda en la llegada al Nuevo Mundo. Cuando comienza el "ciclo del azúcar" en la conquista de las nuevas tierras se relaciona también con otra cultura antigua, la africana, que sobrevivió "gracias a su música, su danza, [sus creencias]" con una gran fortaleza. También asume la cultura afro-caribeña de Santo Domingo y Puerto Rico. El hispano es, en definitiva "la complejidad creada 'entre' los borders de muchos mundos, 'entre' los intersticios de muchas culturas" (p. 239). Borders como el "entrecruce de horizontes" de Gadamer, "un «espacio» entre muchos mundos, que la subjetividad (intersubjetiva) del actor vive simultáneamente, articulándolos, siendo todos ellos «mi mundo», «nuestro mundo», en la solidaridad del «estaren-casa» hegeliano, pero «exterior» al mundo exterior de los «anglos»" (p. 242, nota 1). Se salvaguardan así el principio de identidad y la posibilidad de apertura al otro.

Precisamente en ese espacio de la Frontera Norte, zona de entrecruzamientos y de hibridaciones étnicas y culturales, se acentúa este intercambio y enfrentamiento pluricultural, con una historia inicial desértica, diseminada ("Tierra de nadie", se le solía nombrar), subalterna respecto de los centros nacionales donde se enfrentaron el poder hegemónico estadounidense y los inicios de la nación mexicana después del proceso revolucionario, lo cual mantiene a la frontera en un nivel de desarrollo precario. Zona contradictoria donde se dirimen los procesos identitarios de los grupos étnicos que se interrelacionan en ese espacio construido por una sociedad plural en formación acelerada, cruzado por los continuos flujos de las poblaciones migrantes.

Sin duda, la noción de frontera es eficaz para mostrar el proceso complejo, contradictorio, de un mundo en transformación, el cual busca su razón de ser en medio de un cambio 
continuo y retante que hace estallar los parámetros de otro sentido que no sea la fragmentación misma

\section{Un deslinde final necesario}

El término frontera se analoga muchas veces con el de nepantla, vocablo de una amplia trayectoria en la historia de la cultura y de la literatura mexicanas, desde la época prehispánica. Nepantla es un adverbio náhuatl que significa 'en medio', 'por el medio'. Unida a otras formas, puede significar 'la acción de estar' o literalmente "caer en medio" de una cosa, o de la gente, y otros matices. También suele ser un estado o una manera de vivir. A diferencia de frontera, que sugiere más directamente la idea de límite, de estar frente al otro, nepantla, al coordinarse con diversos componentes morfológicos, tiende a manifestar el encuentro, la posibilidad de 'amarse mutuamente' o 'entre sí', 'saludarse o perdonarse mutuamente', e indica la investidura del sujeto de una función mediadora, como mensajero entre dos personas. El acento se pone en la capacidad religante, solidaria, y en 'llamarse', 'excitarse', 'animarse mutuamente' a la acción ${ }^{18}$. En cambio, la óptica en frontera denota más directamente la diferencia, el registro de las modalidades múltiples y aun de las contradicciones que buscan conjugarse para conformar un tejido social más humano.

Cabe pensar entonces que, en el plano diacrónico de la historia, alcanzar una concreción social y particular nepantla, implicaría pasar por un proceso de transformación en frontera. Donde nepantla supondría la culminación de la búsqueda; la concreción de la utopía.

UNA HISTORIA Y UNA ESCRITURA EN FRONTERA: LOS RELATOS de Luis Humberto Crosthwaite

Más allá de su región de origen, Luis Humberto Crosthwaite (Tijuana, 1962) pertenece a la llamada Generación de los ochenta, en México, que surge de un pasado inmediato claramente marcado por la condición de frontera.

18 Rémi Siméon, Diccionario de la lengua náhuatl o mexicana, trad. J. Oliva de Coll, $1^{\text {a }}$ ed. en español, Siglo XXI Editores, México, 1977, s.v. 


\section{Pasado inmediato de la generación}

En la década de los años sesenta ${ }^{19}$ se intensifican en México los signos de la disonancia social ya presentes en los cincuenta (escisión y transformación de la estructura familiar, la brecha generacional ligada a un fuerte crecimiento demográfico y a una distribución no equitativa de la riqueza y de los medios que podrían dar cauce a una juventud progresivamente numerosa, rebelde porque no ve claras las posibilidades de salida). El hecho se reproduce en los Estados Unidos y en Europa por la situación compleja que provoca una política desarrollista capitalista que entra en crisis, y los efectos de la Segunda Guerra Mundial con su secuela de violencia bélica, la llamada Guerra fría que se inició con la Guerra de Corea (1950-1953). La alteración sucesiva del orden no logró que se produjera el cambio necesario, ni que se colmaran las ambiciones y deseos de la sociedad ni de los hombres y mujeres vulnerados en su interior. Los cambios muchas veces erráticos de la entrada a la Modernidad desplazaron y minaron las bases de los sistemas anteriores, pero no generaron las alternativas viables que favorecieran un desarrollo armónico, ni económico ni humano. La creciente norteamericanización de la sociedad en todos sus aspectos, crea tensión en las relaciones de los diversos sectores y estructuras. En México se agudiza y adquiere marcas particularizadas por la situación de frontera entre ambos países. Los problemas entre éstos se habían intensificado en 1950 con la entrada ilegal de trabajadores mexicanos a Estados Unidos en busca de nuevas oportunidades de trabajo. Aunque en 1951 se llegó a firmar un nuevo tratado para contratar braceros mexicanos, un año después las dificultades aumentaron, y México se negó a firmar un tratado de cooperación militar con el país vecino. En 1958, último año del presidente Adolfo Ruiz Cortines, estallaron varios disturbios estudiantiles, dos grandes huelgas (la de telegrafistas y la de los ferrocarriles), y otra de los trabajadores del petróleo. Adolfo López Mateos fue electo presidente ese mismo año, y en 1959 el Movimiento 26 de julio, encabezado por Fidel Castro, triunfa sobre el régimen del dictador Batista en la isla, acontecimiento que incide en la historia de nuestros países y en la juventud.

19 Sobre los antecedentes históricos, cf. Lorenzo Meyer, "La encrucijada”, en Historia general de México, $1^{\mathrm{a}}$ ed., El Colegio de México, México, 1976, t. 4, pp. 201-283 (hay varias eds., la última, con algunos cambios, es de 2000). También las tablas cronológicas, de la versión publicada en Historia de México. Etapa nacional, SEP-CONAFE-CNIE, México, 1976, pp. 102-115. 
Hacia finales de 1960 surgen otros disturbios estudiantiles en México. Esta reiteración de la rebeldía estudiantil responde a una situación compleja que toca diversas esferas y problemas. Indudablemente apunta a una problemática educativa que no satisface las aspiraciones y demandas relacionadas con las transformaciones al sistema que exige su tiempo, problemas que persisten, con sus variantes, hasta nuestros días. En medio de este ambiente, no sorprende que el descontento estudiantil se canalice y manifieste en contra de la frustrada invasión a Cuba por los Estados Unidos en 1961, a un año de la elección de Kennedy como presidente. La situación es difícil de sortear para la política exterior de México. En 1962 el país condenará la presencia de cohetes soviéticos en Cuba. Internacionalmente contribuyen a la atmósfera de inestabilidad las guerras civiles en África y en Argelia, al mismo tiempo que se pone en órbita el primer satélite americano en 1962 y se nivela así la hazaña soviética que lanzó el primer satélite tripulado, en 1960. En el territorio nacional hay síntomas claros de malestar (el asesinato de Rubén Jaramillo y de su familia en ese año, la creciente violencia en el estado de Guerrero y en otros puntos, como Atoyac y Chiapas, en 1967). Mientras tanto, Estados Unidos interviene en Vietnam en 1964 e invade la República de Santo Domingo en 1965, lo cual motiva la censura de nuestro país. En defensa de las posibilidades de pesca y el derecho territorial de las aguas, México y Estados Unidos negocian, tras varios incidentes con barcos pesqueros norteamericanos, la exclusividad de derecho sobre una zona de pesca de 12 millas para cada país. Se suceden los golpes militares en Argentina y Grecia, se inician incidentes bélicos entre Israel y el Estado árabe y en Nigeria la guerra civil por su independencia. La muerte del Che Guevara en Bolivia convierte su imagen en un icono que se populariza, sobre todo entre la juventud, hasta el presente. Otros factores que contribuyen a degradar las condiciones de vida en las sociedades modernas e industrializadas son los problemas del medio ambiente y los demográficos, los cuales alteran el equilibrio ecológico necesario para salvaguardar los niveles de vida que exigen el desarrollo humano, vegetal y animal.

La atmósfera de tensión y contradicciones fuertes estalla en el movimiento estudiantil de 1968, casi simultáneamente, en París, Estados Unidos, Alemania y México, ahora bajo la presidencia de Gustavo Díaz Ordaz. Antecede la "renuncia forzada" del doctor Ignacio Chávez como rector de la Universidad Autó- 
noma de México, lo cual tensa la atmósfera de inestabilidad en el recinto más representativo de estudios superiores en el país.

El '68, como suele denominarse al Movimiento estudiantil, culmina en la matanza de estudiantes y civiles en Tlatelolco, el 2 de octubre, seguida por la celebración de las Olimpiadas, acto que sacude las bases mismas del sistema en crisis y marca indeleblemente la memoria histórica del país. "La manifestación del silencio", el 13 de septiembre de 1968, fue el símbolo en que se concentró la intensidad de la historia. El acto multitudinario, convocó a los más amplios y diversos sectores universitarios, públicos y privados, a los que se sumaron representantes de toda la sociedad. La manifestación culminó en el zócalo. El orden y la dignidad del acto lo grabaron en la memoria histórica por su ejemplaridad. Nada como la eficacia solemne de la crónica de Carlos Monsiváis ${ }^{20}$, precisa y poética, para evocarla. Fue la dignidad nacional cristalizada en el gesto de los jóvenes, lo que apeló al interior de los hombres y mujeres de diversos sectores. A la voz del silencio voluntario se sumó la palabra escrita de los volantes repartidos:

Pueblo mexicano: puedes ver que no somos unos vándalos ni unos rebeldes sin causa, como se nos ha tachado con extraordinaria frecuencia. Puedes darte cuenta de nuestro silencio, un silencio impresionante, un silencio conmovedor, un silencio que expresa nuestro sentimiento y a la vez nuestra indignación.

El comentario del cronista-escritor contrapuntea el discurso estudiantil, lo explica, lo amplía, lo reproduce:

Quienes desfilan, prepararon los adjetivos que encomian su intento (impresionante, conmovedor, expresivo)... Los preparatorianos y los de las vocacionales, los más jóvenes, han elegido el esparadrapo, la tela adhesiva sobre los labios para acentuar su silencio: un clarísimo y violento afán simbólico los domina. El silencio existe como una llamada de atención: nuestra marcha es un discurso. El silencio existe como un castigo: denunciamos y liquidamos décadas de verbalismo inepto. El silencio existe como un autocastigo: confesamos las insuficiencias de nuestra relación con el pueblo. Simultáneamente se procede a la creación de un vacío, donde desaparecen las autoridades morales y la educación en el

20 "La manifestación del silencio", en Días de guardar, 4 ed., Era, México, 1971, pp. 268-275. 
respeto, donde se desvanecen las soluciones al gusto de todos y la paciencia ante la adversidad...

El mensaje de pronto se aclaró, se despojó de moralejas, resultó nítido: en la petición de diálogo, había la animada disposición de forjarse un lenguaje; en la adopción del silencio se delineaba la voluntad de adquirir autonomía en el sonido, de enterarse al fin de cuál podría ser el sonido de una sola mano aplaudiendo, de captar el significado de las voces emitidas con decisión autónoma, de chingada a concientización, de pendejo a mediatización. El silencio era desdén ante el atropello, el saqueo semántico: desdén ante el cinismo que culminaba en el mandato... (pp. 269-272) ${ }^{21}$.

\section{Antecedentes literarios y culturales $^{22}$}

En la literatura predomina la búsqueda de nuevos caminos de expresión y de horizontes más cosmopolitas. Destacan las novelas y textos urbanos en los cuales la ciudad es el nuevo centro donde se problematizan los diversos sistemas de relación, y se gestan, en un proceso contradictorio y difícil, las transformaciones necesarias que ponen en frontera las estructuras socioeconómicas y culturales. Esto llega a cuestionar la propia identidad, tanto individual como colectiva. La atención se focaliza en la dinámica versátil, múltiple y contradictoria de la Ciudad México con su poder de centralización, pero también en otras ciudades del país donde se están produciendo fuertes transformaciones de las estructuras modeladoras de la familia, de la vida cotidiana y de la sociedad en general, como es evidente en la Literatura de la frontera Norte. Estos procesos son producto de los cambios radicales que supuso el movimiento revolucionario, el parteaguas del ' 68 y sus derivaciones, la migración interna hacia diversos puntos sobre todo urbanos del país, y la migración externa, orientada principalmente hacia los Estados Unidos, la cual condiciona incluso la migración por la frontera sur, en tanto los migrantes procedentes de centro y sur de América tienen muchas veces como objetivo final el paso hacia los Estados Unidos.

${ }^{21}$ La secuela histórica de la violencia del Jueves de Corpus, en la Ciudad de México, el 10 de junio de 1971, al inicio de la presidencia de Luis Echeverría, legitima aún más el discurso de la subversión del '68.

${ }^{22}$ Entre otros, cf. José Agustín, Tragicomedia mexicana. La vida en México (1940 a 1970), Planeta, México, t. 1, 1990; t. 2, 1992. También, Carlos MonSIVÁis, "Notas sobre la cultura mexicana en el siglo xx", en Historia general de México, t. 4, pp. 305-476. 
Es desde esta perspectiva, y con otros componentes que permiten deslindar simpatías y diferencias entre el pluralismo y diversidad de la producción cultural en el México contemporáneo, que podemos aproximarnos a la Literatura de la frontera Norte en México, en diálogo que no en ruptura, con la llamada literatura del centro y otras manifestaciones literarias nacionales y universales. En esta búsqueda, el vector de análisis más importante para la creación y para la lectura crítica es el lenguaje, en toda su complejidad de transformaciones, adaptaciones y contradicciones que hacen posible la expresión certera de un período de transición y emergencias, decisivo para poder hacernos sujetos activos de nuestro proceso histórico. Más que entre "la tradición y el canon", precisaría la dinámica transgresora de nuestra literatura, "entre la tradición, el canon y la marginalidad". Es este hibridismo particular lo que subyace a los procesos innovadores de la literatura en diálogo constante, hondo, con el río de nuestro devenir histórico. En ese sentido, la investigación literaria revela cómo la literatura se adelanta a los hitos que escogemos finalmente para signar los momentos más significativos de la historia literaria. La cronología muestra, por ejemplo, que ya en 1965 aparecen tres novelas: La tum$b a$, de José Agustín; Gazapo, de Gustavo Sáinz y Farabeuf, de Salvador Elizondo. En 1966 De perfil, de José Agustín, José Trigo, de Fernando del Paso, y en 1967, Cambio de piel, de Carlos Fuentes y Morirás lejos, de José Emilio Pacheco. Podríamos sumar otras obras en este período que refuerzan lo que me interesa señalar ${ }^{23}$. A José Agustín y a Gustavo Sáinz se les inserta en los márgenes, en la mal denominada Literatura de la onda ${ }^{24} ; \mathrm{Fa}$ -

${ }^{23}$ En 1968 confluyen S. Elizondo, El hipogeo secreto y de J. Agustín, Inventando que sueño, y a comienzos de 1969, Obsesivos días circulares, de Gustavo Sáinz y El apando, de Revueltas.

24 En 1971 Margo Glantz pretende nombrar a la generación que expresó más directamente la protesta y transgresión juvenil, a partir de los años sesenta. El acto de nombrar llamó la atención sobre el grupo, lo cual tiene algo de positivo, aunque lo hiciera de manera muy polémica. En realidad, más bien enaltece la literatura dominante que viene desde los años cincuenta y subraya la transitoriedad de las tendencias que pretenden expresarse desde los jóvenes, sus inquietudes y búsquedas ("Onda y escritura. Jóvenes de 20 a 33”, que hoy podemos consultar en la Biblioteca Virtual Miguel de Cervantes). En un segundo artículo ("La onda diez años después: ¿epitafio o revalorización?”, Texto Crítico, 1976, núm. 5, 88-102), pese a su interés en revisar el punto de vista primero, recae en lo mismo, no sin ambigüedad. Por un lado reproduce ejemplarmente "el estilo" de la 
rabeuf y Morirás lejos se consideran novelas de experimentación -de ruptura- y la de Fernando del Paso se asocia más bien con la de Fuentes, transgrediéndola -tendencia más próxima al canon. Sin embargo, son todas novelas que ponen de manifiesto un estilo generador de estrategias de composición y escritura novedosas con el lenguaje, acorde con lo que buscan expresar. Esa adecuación de palabra y expresión con un máximo de economía poética ligada a la intención que rige cada texto, es lo que les confiere su calidad literaria. Es decir, ya la literatura busca los nuevos y necesarios caminos de expresión para un nuevo tiempo y lo hace con autores activos de amplia trayectoria (Pacheco, Fuentes, y también Revueltas, Yáñez), y aquellos que emergen directamente del presente y logran manifestarlo más directamente en una voluntad de cederle "la voz y la palabra", con el distanciamiento estético que permite objetivarlo y darle su particularidad y su dimensión humana, universal. El mayor o menor distanciamiento del presente supone, de acuerdo con la intencionalidad expresiva, retos distintos a la escritura y al lector. Captarlo y poder expresarlo nos llevará, en un caso, a la concreción de un texto con calidad literaria y, en el otro, a una lectura crítica, sensible y penetrante.

Otros dos lenguajes culturales decisivos en los escritores jóvenes de estas décadas son la música popular y el cine. Ante un tiempo que se nos escapa porque estalla la cotidianidad y todas las convenciones de estabilidad reconocidas antes, sin que las sustituya un nuevo orden, el lenguaje se expande y asume otras posibilidades de expresión dominantes como caracterizadores de ese tiempo en crisis. En los años cincuenta la música ran-

Onda, de suyo eficazmente expresivo, pero recae en el mismo juicio anterior al cuestionar su posibilidad de permanencia. Hoy por hoy es evidente que las rupturas juveniles de entonces se proyectan en gran medida en la fuerza que muestra la Literatura del Norte, la cual, a su vez, asume la escritura de la tradición dominante (Rulfo, Revueltas, Pacheco...). Véase, sobre este punto, José Agustín, "La onda que nunca existió”, RCLL, 2004, núm. 59, 9-17, texto con el que coincido básicamente. También, Tragicomedia mexicana. Entre 1970 y 1976 la "literatura contracultural" produjo varias obras importantes de Parménides Saldaña, Héctor Manjarrez, Federico Arana y José Agustín, las cuales se suman a las primeras del propio Agustín, Gustavo Sáinz, Parménides, y también de Juan Tovar, René Avilés Fabila, Jorge Arturo Ojeda, Luis Zapata y otros. La temática se diversifica y enriquece. Editoriales como Joaquín Mortiz se abren a las nuevas tendencias; le siguen Era y Siglo XXI. El deslinde fino y la investigación detenida de estos procesos es una tarea aún pendiente de nuestra literatura. 
chera toca su límite con su ideología machista ("la vida no vale nada, pero sigo siendo el rey"), y transita después, con la voz, la palabra y la actuación de José Alfredo Jiménez, del rancho al medio urbano en una situación límite. Dice José Agustín, hablando de las "mutaciones terribles" del género: "las canciones 'rancheras' de los años setenta con mucho rebasarían el espectro del machismo para llegar a las antípodas en el caso de Juan Gabriel" (cap. 1, p. 146). Lo dominante hasta nuestros días será la presencia de la música norteamericana que corresponde a "la influencia de Estados Unidos [la cual] se dejaba sentir con fuerza acumulativa en casi todos los órdenes de la vida mexicana" (id.): lo que quedaba de las grandes orquestas (Ray Anthony, Billy Mae, Ray Coniff) y cantantes como Eddie Fischer, reproducido por Luis Alcaraz, Pablo Beltrán Ruiz y Pablo Esquivel se sustituyó por los signos de contracultura de los jóvenes norteamericanos que "causaría estragos aquí y en todo el mundo" en los jóvenes, en contra de la rigidez derechista y anticomunista y la rigidez de los "formalismos sociales". Se instala el reino del rocanrol, símbolo de energía, vitalidad, y de alta tecnología con su "irrebatible sensación de poderío, forma musical que venía de los profundos estratos populares estadounidenses: la vida marginal de los negros en las ciudades y la tradición blanca del campo, que [incorporó] la improvisación y la atmósfera marginal del jazz". Fue el "lenguaje universal" de la rebeldía de la juventud y como tal prende en México a partir de 1955, por analogía con el descontento y frustración creciente de los jóvenes ${ }^{25}$.

Por otra parte, la Literatura del Norte en México se identifica cada vez más con la situación de frontera y de la migración constante entre uno y otro lado. La frontera adquiere connotaciones fuertemente identitarias y coloca en umbral las relaciones entre los hombres y mujeres "del lugar". Como el exilio, vivir en la frontera condiciona la cotidianidad y los procesos sociohistóricos. Presupone la interacción continua con un contexto plural, cambiante, que tiende a la hibridez y al mestizaje étnico y cultural. También puede reforzar las diferencias o propiciar la aparición gradual de una nueva identidad (¿el caso chicano?) que asume ambas orillas y busca autonomizarse. En todos los casos, la lengua y los diversos lenguajes culturales son

25 Sobre la magnitud y la proyección en México de esta situación, cf. J. Agustín, Tragicomedia mexicana, t. 1, pp. 146-150. Para la década de los años sesenta, véanse también las pp. 249-252. 
reveladores privilegiados de estos procesos. Y no menos importante, de los procesos interiores que transforman la vida de los sujetos, su percepción del mundo y su proyección en el proceso histórico social. El suceso es determinante en ahondar la brecha generacional y la rebeldía que en la siguiente década determinaron una nueva concepción de la vida. Otro hecho significativo es el cambio radical de la moda en consonancia con los nuevos modelos clasemedieros: chamarras de piel negras (Marlon Brando, El salvaje); después rojas; pantalón de mezclilla, calcetas blancas, motocicletas (James Dean, Rebelde sin causa).

No obstante, cabe decir que la Literatura del Norte ofrece un mosaico plural de modalidades de escritura. La situación de frontera incide sobre la vida y la producción cultural -incluso en aquellos casos en que se pretende escribir de espaldas a ella-, pero además incide en la Literatura nacional (de la Ciudad de México y de otras regiones del país) y la de otros países. Me parece importante señalar que, al mismo tiempo que asume intertextos cultos y populares de su presente, privilegia textos y autores de la mejor tradición hispánica nacionales e internacionales (notablemente Juan Rulfo, José Revueltas, José Emilio Pacheco, José Agustín..., pero también Cervantes, Lope de Vega, temas de la mística, el Carpe diem, el Ubi sunt, los cuentos tradicionales...). Comparte, de manera significativa, nexos intertextuales con el cine, la música y la literatura norteamericanas, como ocurre en otras regiones del país, aunque con mayor intensidad en la Ciudad de México.

\section{¿Cómo Se inserta la escritura de Luis Humberto CROSTHWAITE EN ESTE CONTEXTO SOCIOCULTURAL?}

Crosthwaite nace en la frontera mexicana, precisamente en los primeros años de la década de los años sesenta, publica a partir de 1988, desde su ciudad: "inventada, mutable, multifacética"; desde su presente y la cotidianidad marginal del entorno (sus calles, sus grupos, sus congales, sus puntos de reunión, su ir y venir entre el otro lado a trabajar y éste, la identidad cuestionada). Narra inmerso en ese presente en tránsito entre dos épocas, la cotidianidad degradada de "Los cholos" ${ }^{26}$, uno de los grupos

26 “Cholo. 'En la frontera México-Estados Unidos se refiere a emigrantes mexicanos de clase social baja. En los sesenta cambió, y se utilizó como un 
del margen, antes dueños del barrio, y ahora en franca decadencia. El ' 68 , dos décadas atrás, estuvo marcado por el estallido de las estructuras socioeconómicas, y nos dio una literatura ensimismada en la búsqueda obsesiva del sentido de un contexto fragmentado, doloroso, múltiple y contradictorio, donde el hombre, lleno de interrogantes hacia sí mismo y hacia el entorno, y las voces de los márgenes se canalizan en la fuerza de un lenguaje que estalla en la oralidad expresiva, directa, de la palabra de la calle. Y ésta se eleva en la concreción poética de una nueva literatura que pide voz. En ese sentido la Literatura del Norte, en frontera, se vincula con la literatura que generaron los más jóvenes, de cara a la crisis, en los años sesenta, pero también asume, como río subterráneo de la intrahistoria literaria que le es propia, textos fundantes de esa identidad que contribuyen a su particularización.

Con una óptica menos nostálgica tal vez que la de Eduardo Antonio Parra, en tanto se sitúa más claramente en el presente histórico con miras al futuro -pero más crítica e irónica-, Luis Humberto Crosthwaite sintetiza una suerte de manual de supervivencia que decanta todo comentario excesivo y se concentra en emitir una serie de Instrucciones para cruzar la frontera. Relatos, título del libro que publicó en $2002^{27}$. El estilo es esquemático, pretendidamente frío, con enunciados reglamentarios y "operacionales" que tienden a asociarse a un mundo "ordenado", de sociedad "desarrollada"; en el relato cobran una función irónica y paródica. El lenguaje se mueve en dos niveles: el de la "recomendación" práctica oficial y el del comentario experimentado que entrevera los datos aparenciales de una sociedad confortable y, al mismo tiempo, en el mismo enunciado, delatan la intención política, la farsa del mundo que representan. El cierre finalmente deja entrever la denuncia plena de las intenciones del sistema del "otro lado" que invierte el paradigma de confort en una cacería de alta tecnología. La advertencia inicial

símbolo de orgullo étnico-cultural, por los movimientos de "poder étnico» en los Estados Unidos"” (J. Cú́Llar, "The rise and spread of cholismo as a border youth subculture", trabajo presentado en Southwest Border Regional Conference's Third Annual Binational Border Governors' Conference [Tijuana, Baja California, México, 21 septiembre de 1982; texto inédito]). Se suele decir que se originó en el movimiento chicano de los años sesenta en Los Angeles, California como marca de identidad nacional y resistencia social, cultural y política.

27 Joaquín Mortiz, México, 2002, pp. 95-125. 
("Piensa en esto: de preferencia no lo hagas", p. 9) que orienta la lectura desde el comienzo, cobra ahora plena significación.

Un mismo tono desestructurante caracteriza la mirada al futuro ¿próximo? del relato "La silla vacía" (pp. 79-94). Todo el texto es un largo diálogo hacia el vacío, o en el vacío, entre un "yo" y un "tú" en que se dirime el sentido del sinsentido de la frontera, producto imaginario del "vacío del yo". Se han perdido los nombres y las palabras para nombrarla. Como pieza dramatizable, pese a los tres personajes que intervienen, y a que se trata de un relato relativamente largo, el lenguaje apenas se levanta del vacío. Si "Recomendaciones", el primer relato, sugiere cierto vínculo con los relatos de ciencia ficción que denuncian, revelando, el sistema deshumanizante de la sociedad moderna del presente, "La silla vacía" cala más hondo y muestra el vacío de los sujetos actuantes. Han desaparecido todas las sillas vacías que representan la multitud en Las sillas, de Ionesco. Y está a punto de desaparecer el lenguaje. Sin duda, el libro de "instrucciones" condensa de manera significativa la visión límite de los efectos de la frontera como línea divisoria entre ambos países.

Antes, Crosthwaite ha escrito Estrella de la Calle Sexta $(2000)^{28}$. Son tres relatos: "Sabaditos en la noche", "Todos los barcos" y "El gran preténder" que, pese a su autonomía, producen al leerlos un efecto de unidad. A su vez, al interior de cada relato, los fragmentos que lo constituyen son autónomos, como minificciones o imágenes. Los relatos corresponderían a tres momentos de una misma historia, historia colectiva que se manifiesta en las múltiples vidas que se van revelando en el acto de lectura. En una breve reseña al libro, Juan Villoro afirma que se trata de "tres relatos que dependen más de las atmósferas que de las tramas" ${ }^{29}$. Al hacerlo, señala una de las claves de esa impresión unitaria. En la particularidad de cada relato que se nos presenta, se va creando una atmósfera que caracteriza el ambiente todo en que se muestra la totalidad. Al mismo tiempo, Crosthwaite ha colocado los relatos en un nuevo orden, distinto al de su tiempo de escritura, lo cual refuerza la idea de una intención explícita de reordenarlos conforme al sentido que persigue. "El gran preténder" fue publicado inicialmente

28 Tusquets, México, 2000 ( $1^{\mathrm{a}}$ reimpr., 2009).

29 "Singuin in da pinche rein. Reseña a Estrella de la Calle Sexta, de L.H. Crosthwaite", Letras Libres, diciembre de 2000, p. 94. 
en 1992, y ahora se publica al final del libro. Es el relato más largo (¿novela corta?). Condensa una nueva ronda del grupo de cholos dominante, cada vez más próximo a su desaparición, y con ello, al final de la concepción del espacio, de la "historia del lugar". El gesto último de afirmación de la supremacía de la "ley" del barrio que cierra el libro, lo sabemos enunciado desde el límite, desde el borde de la frontera de la propia identidad. El fragmento anterior (p. 149) lo sugiere en apretada síntesis metafórica:

El invierno comienza su entrada en el Barrio. Los morros dejan la esquina y se refugian en un lote baldío. Buscan llantas viejas y forman hogueras bajo la luna. Se levanta un humo negro que se esconde en la oscuridad, empujado por el aire, rumbo a los otros barrios.

Hay sin duda una sugerencia de unidad, de vínculo entre los barrios, ahora en la paz de ese cierre de comunión y despedida: "Los morros rolan una botella de tequila, se soban las manos, se acercan al fuego". La luz y el silencio que los une en la noche crea una atmósfera y una relación fuera del tiempo, por un breve lapso: "La lumbre hipnotiza. A veces no hay nada que decirse y la lumbre es la única que habla, que recuerda. Los colores naranjas y amarillos consumen las llantas. La noche se prolonga, no parece acabarse" (las cursivas son mías). Uno del grupo asume la entrada del tiempo real de la despedida. No hay autoritarismo en la voz porque ésta responde a un consenso implícito: "Alguien sugiere que ya es hora de partir. Simón, ya es hora, dicen todos. Pero se quedan un rato más esperando que las llantas mueran. Después el frío arrecia, no respeta, y es mejor irse a rolar: mañana es día de trabajo". Cierra el texto la frase aislada final: "Las despedidas son breves".

Es inevitable pensar en el tipo de relación que Juan Rulfo ha cristalizado entre el puñado de hombres marginales caminando por el llano seco en "Nos han dado la tierra" 30 . No sorprende. Los textos de Rulfo constituyen uno de esos intertextos fundantes en la escritura de Crosthwaite y de otros autores del norte, evidente, por ejemplo, textualmente, en el título y el con-

30 J. Rulfo, El Llano en llamas, $2^{\text {a }}$ ed., revisada por el autor, F.C.E., México, 1955, pp. 15-20 ( $1^{\text {a }}$ ed., 1953). 
tenido mismo de la novela de Élmer Mendoza (Culiacán, 1949), Cóbraselo caro $(2005)^{31}$.

Al colocar "El gran prétender" al final, Crosthwaite es fiel a su voluntad como autor de tener claro, previo al acto de escritura, su final: "Soy muy correcto en el sentido de que no me gusta empezar a escribir sin saber que la historia va a ser terminada". Sabe que el texto, y la literatura en general, no corresponde a un sentido acabado, pleno en su significación. Es procesual y siempre abierta en términos del sentido. Se mueve más en la línea del deseo y de la búsqueda. Pero cada fragmento se autonomiza en la medida en que se orienta a un cierre de la escritura, de la forma. Es la frontera que toca los límites de su contexto, pero no indica finitud. Veremos cómo hay otros detalles de la escritura que contribuyen a este efecto de fragmentación y unidad entre los relatos. Comentaré primero el espacio en que se concentran las tres narraciones, el cual se precisa desde el título del libro, y se describe en el primer relato, y después $e l$ punto de vista y el protagonista.

\section{El espacio y EstrelLa DE LA CALLE SEXTA}

El libro, en su conjunto, muestra la historia de la cotidianidad en el espacio de la calle, propio de los diversos grupos que conforman la colectividad. La economía textual focaliza la acción en la Calle Sexta que, sabremos, funciona como una puesta en abismo de otros espacios equivalentes en el entorno. Esto crea el efecto de una espacialización que corresponde, en el presente de la escritura, a un tiempo detenido, repetitivo, de rituales en decadencia que van perdiendo vitalidad. Hay movimientos en ese microcosmos citadino que la escritura deslinda. Y hay un fluir de grupos y personas que vienen del otro lado de la frontera,

31 En el primer fragmento de Pedro Páramo, de JuAn Rulfo, la madre indica a Juan Preciado, antes de morir, que exija a su padre, "Lo que estuvo obligado a darme y nunca me dio... El olvido en que nos tuvo, mi hijo, cóbraselo caro" ( $2^{\text {a }}$ ed., p. 7). JUAN Villoro hablando del lenguaje que utiliza Crosthwaite, establece una analogía con el tratamiento del lenguaje en Rulfo, en la medida en que ambos crean un lenguaje oral verosímil, muy elaborado literariamente, en su aparente sencillez: "Los batos de Crosthwaite descienden de los campesinos de Rulfo y comparten su áspera elocuencia. No estamos ante un espejo indiferente del habla, sino ante un consumado artificio; el autor ecualiza el lenguaje coloquial en su consola y lo transforma en una rigurosa forma del estruendo" (art. cit., p. 94). 
sobre todo los fines de semana, en el primer relato del libro, que quedan como fondo, porque la escritura sigue de cerca el grupo de los cholos, con la óptica del personaje principal que observa sentado a la puerta de un bar en la Calle Sexta. Pero nada parece cambiar sustancialmente que no sea los retrocesos al pasado que inciden en el presente para entenderlo y los síntomas de caída que se dirigen al final.

El primer relato, "Sabaditos en la noche", nos sitúa en el espacio característico de todo el libro. El título remite a un tiempo marcado en la tradición de México y de otros países para el ocio, la bebida, el baile ("sabadito alegre"), al finalizar la semana laboral. El espacio en que ocurre la acción, la Calle Sexta, es una de las calles céntricas que atraviesan la Avenida Revolución en Tijuana. En ella, antes y ahora, se debate y muestra la identidad de la sociedad y de los habitantes. Ayer mayores; hoy predominantemente jóvenes. Y siempre los turistas gringos que cruzan la frontera cada sábado.

En el presente de la historia del lugar, fuera del ámbito ficcional, una informante, Lorena Mancilla, señala la clave de los cambios en la economía y la dinámica social:

[Antes, en los '90], ninguna mujer se habría atrevido a usar una falda o una blusa sin mangas si no quería correr el riesgo de ser confundida con una fichera. Siempre íbamos en grupo, era tradición para muchos estudiantes salir de cantina en cantina iniciando el tour en la zona norte y terminándolo en la Calle Sexta. Hoy, para los visitantes veteranos puede resultar un shock ver cómo la escena y la gente ha cambiado... El cambio radical vino con la apertura de La Mezcalera en enero del 2009, la cual fue seguida por muchos otros bares. Y aunque todo ello es fabuloso para la economía tijuanense, los nuevos lugares pueden sentirse muy raros, como prototipos esterilizados, implantados a la fuerza en un lugar que nunca tuvo necesidad de ellos, designados para satisfacer a un mercado de hipsters de clase media-alta, los mismos que en otro tiempo, nunca, ni por error, habrían visitado el centro por considerarlo un lugar pobre, sucio, peligroso, y ahora hasta cenan tacos de chile relleno en los puestos de las esquinas (pp. 3-4).

Lorena admite que tiene "sentimientos encontrados hacia la nueva popularidad de la Calle Sexta”, y señala que también ha sido la forma en que "nuevas generaciones de tijuanenses reclaman nuevamente su ciudad y su derecho a la diversión, a sentir que están seguros...", y destaca que, 
lo más atractivo de visitar el centro en la noche es la diversidad, hay de todo para cualquier gusto, excepto corridos de narcos. Hay música industrial, pop de Japón, new wave, cumbias, canciones norteñas de amor, pop electrónico de España, una tocada ocasional de bandas locales y extranjeras, o Djs.

No obstante, aún en el testimonio de los jóvenes, hay nostalgia del pasado inmediato transformado o transgredido, ligado a una identidad:

Y, aunque las opciones siguen creciendo, no hay nada como explorar las cantinas viejas; cuando uno se encuentra con un lugar que tiene la rockola llena de canciones de José José, paredes de espejos, booths de vinil, flores artificiales, una minúscula pista de baile vacía, un baño limpio y cervezas de dos dólares... es posible olvidarse de la economía, del amor, del crimen y de haber dejado el carro en un estacionamiento que cierra a la 1:00 a.m. ${ }^{32}$

Alberto Montes recogió el testimonio de varios informantes en la zona de la Calle Sexta. Concluye que ahora hay más ambiente para los jóvenes en un espacio en que predominaba la gente mayor. La afluencia de los jóvenes se ha incrementado en un $80 \%$ gracias a la promoción por las redes como Facebook y Myspace, a la calidad de los conciertos y eventos y a un nuevo concepto de los establecimientos. La mayoría de los visitantes son jóvenes tijuanenses y no turistas como los que frecuentaban la Avenida Revolución, ahora en decadencia ${ }^{33}$.

El texto de ficción de Crosthwaite se sitúa en el tiempo límite antes de los cambios de este lado de la frontera. De ahí el tono de elegía y de nostalgia que caracteriza su enunciado. Sabemos que en el hoy de la ciudad persiste el salón de baile y bar, "La Estrella". En el pasado inmediato el barrio era una zona a la defensiva; cerrada para lo ajeno que no tenía cabida. ¿Impenetrable? Más bien ensimismada en su poder excluyente, lo cual ha provocado un estado de alerta que cada vez se sume más en un proceso autodestructivo (la guerra de los grupos,

32 Lorena Mancilla, "El revival del centro en Tijuana", en Santiago Reader. Tijuana en español, 12 febrero 2010, p. 8. Nacida en Tijuana en 1975. Licenciada en filosofía, actualmente imparte cursos de ética y literatura en Tijuana. Fue propietaria de una tienda de puros en Rosarito hasta que la economía local se colapsó.

33 Alberto Montes, "Repuntan bares en Calle Sexta por redes sociales", en El Informador de Baja California, 14 julio de 2010. 
las bandas). En el cap. 4 (p. 21), el protagonista se dirige al tú que puede ser el lector o el bato que le escucha al interior del texto. La descripción es precisa: la de la geografía y la del conglomerado humano, y está salpicada de humor ante los demás y ante sí mismo:

Te voy a decir cómo es esta calle, cómo es mi esquina, cómo es la raza que pasa por aquí en las noches... la calle es una línea recta, sucia, rodeada de cantinas, farmacias, hoteles, congales, restaurantes y muchísimos lugares que venden artesanías. No tiene una iglesia o una cruz roja que la redima y la salve del infierno cuando se muera.

Mi esquina está en la Calle Sexta, no es distinta a otras esquinas en la calle Quinta o en la Tercera, la diferencia recae en que yo estoy sentado aquí todos los sábados mirando a las beibis. La raza es la misma: la mayoría son gringos gritones, morros que llegan en montón, que se meten a un bar o un cabaret y que salen emborrachecidos y más estúpidos que cuando entraron.

Las morras gringas me ignoran como princesitas, ya ni me acerco porque no tiene caso. Así les hable en inglés o en chino se hacen las desentendidas...

Así que mejor me dedico a las mexicanitas que son más corazón, menudo, chuleta y, sobre todo, teik not, mi extraordinaria y mortal debilidad en el universo... favor que me hacen al fin y al cabo por estar ahí adornando el mundo con su presencia, como si fueran foquitos de navidad en el árbol de mi vida (pp. 21-22).

También menciona la raza de los polis que por ahí desfilan. Ellos se elevan pocas veces, y se arrastran y agachan como corresponde a su naturaleza.

En ese mundo bajo, subalterno, el narrador dignifica a la mujer (prostituída, pero hermosa como Laurita, humanizada). Subyace la estructura de poder a nivel nacional y la frontera determinante. No obstante, la focalización de la escritura está puesta en la cotidianidad de las relaciones en el espacio acotado de la Calle Sexta, lo cual enmascara, momentáneamente, el efecto desintegrador de la problemática mayor, ahora implícita. La escritura facilitará que se muestren las contradicciones del sistema y que éste se reproduzca con aparentes variaciones en la microhistoria. Así, al interior del barrio se deslindan desigualdades que definen centros de poder. Esto se percibe más en función de lo económico y en las posibilidades de ascenso en la escala social. 
El capítulo siguiente (5, pp. 24-25) revela el envés del tapiz. Tijuana es el gran mercado. Un gran antro donde todo está en venta. La descripción barroca, abigarrada, es un alarde de la escritura. Rompe toda posibilidad de racionalidad porque la mercancía humana desborda los límites del orden. El ritmo se acelera y aglutina fragmentos de una humanidad que se desplaza ante la retina del narrador testigo que está en la más radical soledad (no puede pensar, no puede recordar). El espacio condena a mirar. Se está en los límites de la pérdida de la identidad en los membra disjecta que se deslizan y confunden sus formas: el cuerpo, las sensaciones, el sexo, los olores, los líquidos, los costales de droga, y

dólares, billetes verdes moviéndose entre dedos deslizándose entre piernas, atrapados en pantaletas y calzoncillos y música, tecno, rap, disco, salsa, rock, norteñas, un paso es una melodía distinta, el catálogo completo, cielo e infierno, la bondad, el carisma, todo está en venta, alimentos, tragos, cuerpos, objetos hechos a mano, objetos importados de tierras lejanas, 'taxi taxi', ¿te gustan los hombres?, ¿te gustan los hombres y las mujeres?, aquí te pierdes o te salvas, aquí descubres tu verdadero yo, el último grito de la moda. -Ser, ¿yu guana taxi?

\section{EL PUNTO DE VISTA Y EL PROTAGONISTA}

Los tres relatos de Estrella de la Calle Sexta, se relatan mediante un narrador testigo y protagonista, lo cual establece la distancia de la mediación entre el mundo que se manifiesta y el autor que está detrás de los acontecimientos. El hombre es un gringo ya mayor que ha escogido voluntariamente colocarse de este lado de la frontera. En este sentido, la perspectiva desde donde se narra no es frecuente en la narrativa mexicana aunque se verifica en Fuentes (Gringo viejo), en escritores extranjeros como D.H. Lawrence, excepcionalmente, y en la tradición popular. Se presenta como observador que a su vez se identifica con ese mundo e interactúa en él. Y lo conocemos como héroe caído que busca en este espacio su razón de ser; su paraíso perdido. La herida desencadenante del drama personal, en el origen del otro lado, es la escisión de la tríada familiar que formaba con su esposa y su pequeña hija. Así inicia el relato. Después sabremos que la memoria conserva intacto el recuerdo del vínculo amo- 
roso que la poesía y la lectura tejía en torno a ellos. La palabra era algo vivo que producía gozo entre los tres. La historia del pasado utópico se irá revelando según avanza el relato, como en círculos concéntricos fieles al centro. En el cap. 15, hablará de sus estudios, su futuro, su familia y sus amigos:

Cuando salí de la escuela nunca imaginé que acabaría en este rollo, tenía el espíritu hinchado de tantos estudios, tenía grandes planes para el futuro, tenía mi familia, tenía mis amigos... Caminaba derechito sin mirar el suelo. Me gustaba la poesía, me cae, así como se oye de ridículo; me gustaba leer poesía y novelas y cuentos y ensayos, todo ese búlchit me encantaba. También a mi esposa. Nos pasábamos la noche leyéndonos leyéndonos mientras la niña dormía, a ver quién se acordaba de los versos más chingones. Era una competencia que ganaba ella por lo general. Citaba un poema que me mataba, un verso pequeñito que nos hacía llorar o guardar silencio. Entonces íbamos ambos, tomados de la mano, y nos asomábamos al cuarto de la niña para asegurarnos que estuviera bien, que la fuerza de ese último poema no la hubiera despertado. Estaba dormidita, en paz con el mundo, su pecho subiendo y bajando suavemente. Sus pestañas rizadas eran lo más elocuente que tenía; porque todo lo demás era chiquitito, una miniatura que comprarías en la casa de muñecas, nariz, pies y manos, no había nada similar o mejor en el universo, nada que se comparara.

De repente se acabó. Así como cierras un libro o una puerta o las manos. Paf. El final (pp. 50-51, las cursivas son mías).

Los diminutivos acentuaron la ternura creciente del enunciado en contraste con la pérdida súbita y total. Entendemos que el oficio presente del protagonista sea el de carrocero, el cual lo vincula a la pérdida: "Cada automóvil chocado que llega al taller es un reto. Es un carro que debo dejar perfecto" (id.). El texto no deja lugar a dudas: "Carrocero. Dedicado a hacer que las cosas sean como fueron, capaz de borrar las huellas de los accidentes, devolver el pasado" (p. 52).

Como sabemos desde antes, la identidad queda ambigua:

La raza de los bares a mi alrededor, los cantineros y los meseros me dicen 'gringo loco' y se ríen... Para comenzar ellos saben que no soy gringo, no como ellos me dicen, ¿ves? El gringo es otro rollo, se cree dueño del mundo; yo no, yo nomás tengo esta esquina, este pedazo de banqueta que es mi universo.

Mi patrón, ese güey sí es gringo, para que veas, a pein in da faquinas. Yo soy otra onda. Claro que no soy de por aquí, cómo 
explicarlo, sí soy gringo y no soy gringo, ¿me entiendes? Éste es mi paraíso. El pasado agrio lo dejo allá en el norte, del otro lado de la frontera, como se dice. Todo se queda en los Unáired, el patrón y toda su gente, y yo aquí le sigo, con mi esquina, semana tras semana (pp. 16-17).

Poco después entendemos que su amistad con el cantinero que a veces tiene función de confesor para él, se debe a que comparten un dolor análogo que les ha cancelado el futuro. Por eso en la mirada del otro, lo conoce y se reconoce. Ambos comparten la nostalgia de los ausentes; en ese sentido, los demás son un conglomerado, como se reveló en el cap. 5. La familia propia está fragmentada. Impera la ausencia del padre, lo cual equivale a la caída del mundo patriarcal, dominante en la narrativa mexicana contemporánea.

Mirar es conocer. El relato ha abierto con un diálogo que ubica al protagonista en su presente de espera y en su atalaya de observador. Desde ese punto se dirige a un interlocutor que puede ser el lector. De inmediato reconocemos el tono presuntuoso o jactancioso característico del poeta trovador en la tradición popular:

Hey, hey, aquí nomás mirando pasar a las beibis. Todos los sábados me encuentras sentadito en esta esquina, tripeando, agarrando mi cura. ¿Ya viste aquella morra? Por eso estoy aquí, mirando, mirando. Qué quieres que haga. Toda la semana en el trabajo aguantando al pinche gringo, its tu mach. Éste es mi único desahogo... Tuve muchas ondas en mi vida, tuve mi esposa, tuve mi hija, tuve mi casonona y mi carrotote. Eso ya pasó, carnal, ya es pretérito... yo no soy como cualquier imbécil que se la pasa guachando a las beibis, nel, soy un imbécil especial, al tiro. ¿Me entiendes? Yo recorrí el mundo, ya nadie me cuenta lo que es bueno y lo que es malo. Yo escogí los caminos y escogí también que mis sábados pasen en esta esquina (p. 13, las cursivas son mías).

El héroe, caído, se dignifica en la afirmación de su libertad. Es lo que veremos en el desarrollo del relato. Él sabe escoger y distinguir la mujer que sobresale del mundo degradado, aunque también es parte de ese mundo en caída que corresponde al final de su tiempo. Para sus conquistas utiliza estrategias que le permiten dominar con el tacto de quien conoce a la mujer y sabe graduar el asedio. También convierte en estrategia el dominio de su saber, de su capacidad de lectura: "hasta que 
ella pregunta ¿'Cómo le haces pa saber tanto?' y le digo 'pos leyendo, mija"'. Al hacerlo es capaz de elevar las expectativas de la mujer, por sobre el contexto que los condiciona. Suscita su imaginación y siquiera esa noche son capaces de tejer la ilusión de un porvenir en armonía con el hombre: "y en su alucine ellas se imaginan casadas con un genio y con muchos hijos que nacen hablando un montonar de idiomas" (p. 15). El amanecer instala una vez más la realidad, la radicalidad de la despedida: "y jamás de los jamases nos volvemos a ver" (id.); una y otra vez.

Los caminos de la vida corresponden a las mujeres. La ausencia o disfunción del padre es lo dominante en el núcleo familiar. El protagonista testigo revela a Laurita y al lector el disparador de su caída:

Soy papá de nadie; fui papá de alguien, pero ya no. Se me acabó la paternidad justo en ese punto de la carretera, mira, aquí donde la curva se vuelve muy pronunciada, donde es peligroso, donde uno debe bajar la velocidad porque si no... A partir de ese instante el camino volvió a cambiar, dio una vuelta en u, se degradó, se acabó el asfalto, se volvió terracería... Así fue como volví a nacer.

Lo silenciado hasta entonces se revela finalmente: él re-nace, y mueren su esposa y su hija (pp. 35-36). Además, recuerda su orfandad a causa de la disfunción paterna. Por eso niega la identificación con la imagen del padre en la foto de familia que hace mirar al bato: "Ah, ¿se parece a mí? Ni de chiste. Mira bien la foto... ¿Tú crees que ese bato se parece a mí?"

Nunca

nunca nunca (p. 42).

La frontera interior es insondable. Entre el padre (la raíz) y el hijo, "un silencio que se mete entre los dos" (p. 39).

También se desestructura la "autoridad" del congal. El Ciruelo, caído, "pierde toda compostura, ya no es el patrón rudo; parece un títere, parece que alguien, un marionetero, lo mueve desde una altura incalculable" (p. 48). Por primera vez se denuncia (se vislumbra) un sentido total de la vida del hombre, una autoridad trascendente, sin embargo indiferente a la zigzagueante condición humana, víctima del máximo "poder". Se ve a sí mismo sin "reflejo", ante su destino. La única imagen 
que reconoce es ficcional. Surge del cine, de una película de Alan Ladd:

Comprendo que ha llegado la escena decisiva, la hora de enfrentarme a Jack Palance... Me levanto de mi asiento y voy a dar el primer paso, desenfundar con la velocidad de la luz. Me faltan las piernas y más bien acabo en el suelo. ¡Sóbate! Desde arriba Beto se asoma y sonríe. -Qué te pasa, güerito, no te andes cayendo.

La verdad es que no ando cayéndome, ya estoy caído. Y con mucha dificultad me levanto. Veo a Laurita saliendo del bar y logro sentarme de nuevo. El Ciruelo regresa a su mesa. Esta vez Alan Ladd estaba borracho. No cabe duda que los tiempos cambian (pp. 48-49).

El pasaje muestra la autoparodia del personaje que remata en la oración final, cuando el amigo le revela que la idealizada Laurita es novia del dueño del congal: "Me gusta este desenlace para que Alan Ladd regrese a su casa y se deje de pendejadas" (p. 49). Más adelante (cap. 18, pp. 58-59), en un fragmento que es prácticamente un diálogo, la amante le pregunta insistentemente por su nombre. Él contesta identificándose con otro artista de cine. Ella le pide que se lo repita y él lo repite pausado: Jean Claude Van Damme ${ }^{34}$. "-Suena bonito, pero me daría miedo repetirlo".

El segundo relato, "Todos los barcos", es breve (pp. 69-75). Sirve de puente entre el relato de "el gringo" y el final, "El Gran prétender". Corresponde a un ritual de paso de la vida adolescente a la adulta de un gringo joven que cumple dieciocho años. Es la gran fiesta que el hermano mayor le celebra con un grupo de amigos. El homenajeado intenta una salida liberadora, pero el final no oculta su fracaso:

Ken recargado en una pared. El piso sucio. ¿Nunca lo limpian? Gira que gira que gira. Contempla las flores: un color rojo, intenso, profundo como ese lugar en el mar donde todos los barcos... ¿cómo era? Camina de regreso al burlesque. No tiene otro lugar a donde ir (p. 75).

${ }^{34}$ Jean-Claude Camille Francois Van Varenger, nacido Bruselas, Bélgica, el 18 octubre de 1960; muerto en 2000. Actor de cine, experto en artes marciales, de notable musculatura, muy taquillero en los años ochenta. Su película más importante fue Timecop, con Sylvester Stallone y A. Schwarzenegger. Escribe, interpreta y dirige, Eagle Path, 1910. Deriva en cocainómano y alcohólico, con problemas de bipolaridad. 
Pareciera que el gringo joven es un signo más de que el destino del otro lado de la frontera, es este lado. Así como en el inicio, el "gringo viejo" decide quedarse en este lado, ante el fracaso del american way of living su vida.

YvetTe Jiménez de BÁEz

El Colegio de México 
